\title{
Butenafine Hydrochloride
}

National Cancer Institute

\section{Source}

National Cancer Institute. Butenafine Hydrochloride. NCI Thesaurus. Code C47426.

The hydrochloride salt form of butenafine, a synthetic benzylamine derivative with fungicidal properties. Butenafine hydrochloride interferes with the biosynthesis of ergosterol, an important component of fung al cell membranes, by inhibiting the epoxidation of squalene. This alters fungal membrane permeability and causes growth inhibition. Butenafine hydrochloride is active against a number of dermatophytes, including Trichophyton rubrum, T richophyton mentag rophytes, Microsporum canis, Sporothrix schenckii, and yeasts, including Candida albicans and C. parapsilosis. 